\title{
Estimating Diet Composition in Sea Lions: Which Technique to Choose?
}

\section{Dominic Tollit and Susan Heaslip}

University of British Columbia, Marine Mammal Research Unit, Fisheries

Centre, Vancouver, British Columbia, Canada

\section{Bruce Deagle}

University of Tasmania, Zoology Department, Hobart, Australia

\section{Sara Iverson}

Dalhousie University, Biology Department, Halifax, Nova Scotia, Canada

\section{Ruth Joy, David Rosen, and Andrew Trites}

University of British Columbia, Marine Mammal Research Unit, Fisheries

Centre, Vancouver, British Columbia, Canada

\section{Abstract}

Reliable estimates of diets are vital to monitor impacts of sea lion populations on their ecosystems and their interactions with fisheries, and to understand the role of food to animal nutrition and health. Approaches include using (1) prey remnants in stomach contents, spews and scats; (2) prey DNA in scats; (3) fatty acid signatures in blubber; and (4) stable isotope ratios in predator's tissue. Each methodology has particular advantages and limitations, many of which can be assessed and improved through controlled captive feeding trials. Analysis of prey remnants from captive sea lion scats have shown significant variability in digestion between and within prey species, which, coupled with preferential regurgitation and enumeration biases, can confound accurate diet quantification, but does not prevent spatial or temporal comparisons. Correction for partial digestion and use of additional structures besides otoliths can provide reliable prey size estimates. Prey DNA can be consistently isolated from soft remains in scats from captive sea lions, and with further development this approach may allow quantification of diet. Genetic methods can be expensive and representative of only one to two 
days foraging (like prey remnant analysis), but may be less affected by differential digestion and can identify prey in scats that could not be identified through structural remnants. Validation of fatty acid signature analysis to quantify diet at longer temporal scales in sea lions is ongoing. This new technique promises to be particularly useful to assess biases in traditional methods, identify the onset of weaning, and highlight the prey that most contribute to lipid reserves. Stable isotope analysis of predator tissues gives only trophic level data, but can provide data on diet changes on many temporal scales. Remote video monitoring of foraging events and lavage/enema techniques can provide valuable diet information, but, like many newer techniques, animal capture is required. Ideally a suite of techniques should be used to study diet. While methods and correction factors developed for Steller sea lions can likely be applied to the other five sea lion species, they should be verified experimentally.

\section{Introduction}

Reliable estimates of diets are vital to monitor impacts of sea lion populations on their ecosystems and their interactions with fisheries, and to understand the role of food to animal nutrition and health. The traditional approach was to examine stomach contents. More recent methods include using hard remains in scats and spews, isolating prey DNA from scats, fatty acid signatures in blubber, stable isotope ratios in predators' tissues, and direct video observation. All methods of estimating diet have pros and cons (Table 1), many of which can be assessed and improved through controlled captive feeding trials.

\section{Methods}

Captive feeding studies with 2-5 year old female Steller sea lions at the Vancouver Aquarium Marine Science Centre have assessed three different methods to quantify diet. In this review, we summarize the findings of these studies, complement them with results from additional captive studies with sea lions, and discuss the benefits and drawbacks of alternate techniques presently being used to study sea lion diet (Table 1).

\section{Prey remains found in scats}

The analysis of prey skeletal structures found in scats (feces) is now the most widely used technique for estimating the diet of pinnipeds, with sagittal otoliths being the most commonly used identifying structure (Frost and Lowry 1980, Olesiuk et al. 1990, Bowen et al. 1993, Tollit and Thompson 1996). However, there remain a number of well recognized problems related to identifying prey without hard remains, differential rates of digestion (hence, recovery), and choice of skeletal structures used to identify prey (see reviews by Pierce and Boyle 1991, Bowen 2000). 


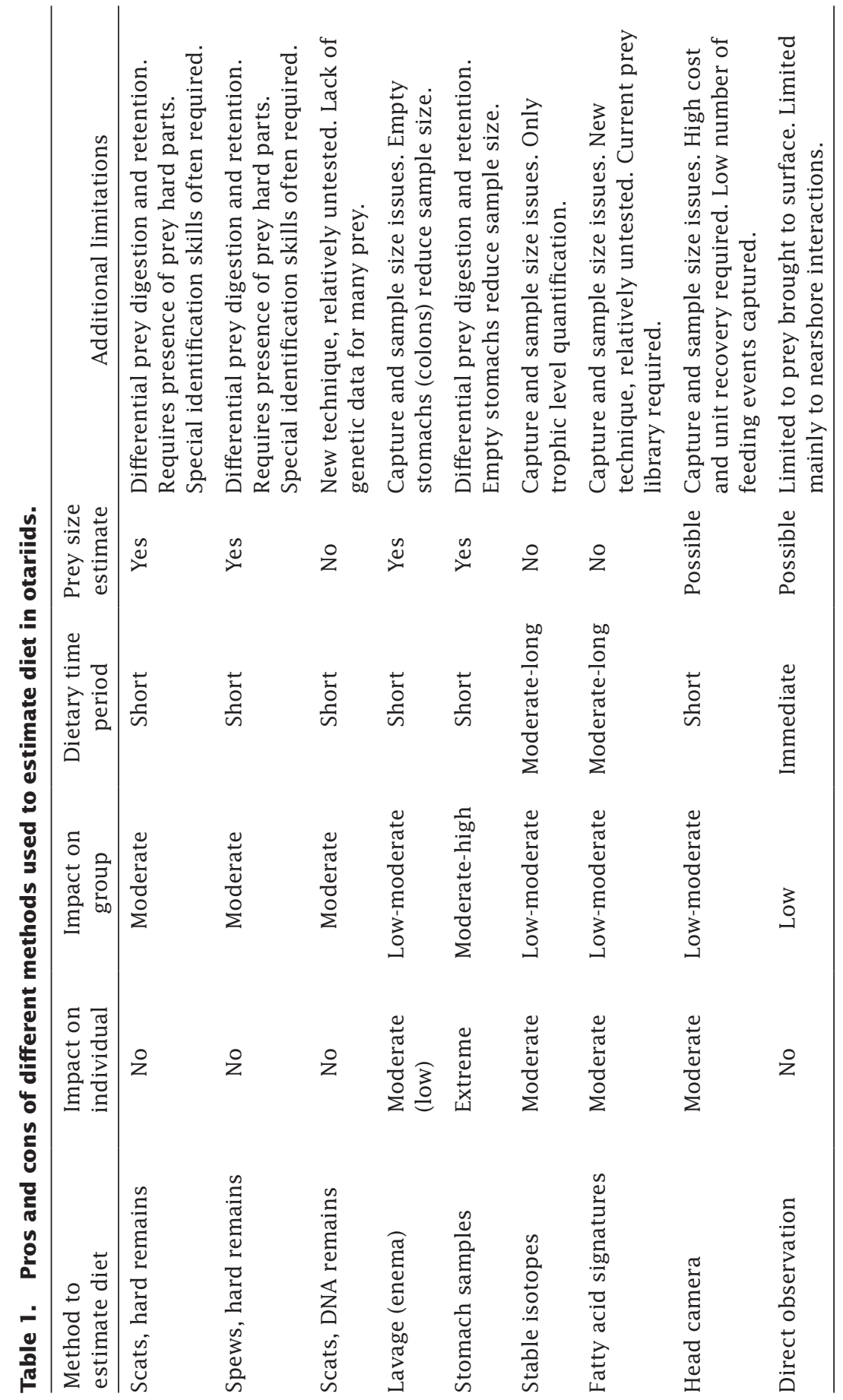


Recent captive studies (e.g., Gales and Cheal 1992, Orr and Harvey 2001, Cottrell and Trites 2002, Staniland 2002, Tollit et al. 2003) were designed to provide numerical and size correction factors to account for the effects of digestion, and to assess the use of different structures and diet indices in describing diet. More recently, multiple bones in addition to otoliths have been used for prey identification from scat, a technique that requires highly specialized identification skills and a complete reference collection. Nevertheless, the technique was believed to significantly reduce the problems associated with differential digestion (Olesiuk et al. 1990). Our captive studies have therefore concentrated on assessing this new approach by feeding both individual single species meals (see Tollit et al. 2003 for methods) as well as replicated meals of mixed and varying species composition.

A total of three replicated meal feeding trials were undertaken at the Vancouver Aquarium Marine Science Centre in the summer of 2003. As in the single species meal feeding trials, experimental meals were preceded and followed by 3 days of herring fillets. Each trial fed for 15 days the same four species (herring, walleye pollock, coho salmon, and capelin) at the same time $(\sim 10: 15$ and $\sim 15: 15)$, in the same quantity (7.5\% body mass per day), but in three different prey ratios (scenario 1 , $67.5 \%, 22.5,7.5 \%, 2.5 \%$ respectively; scenario $2,22.5 \%, 67.5 \%, 2.5 \%, 7.5 \%$ respectively, and scenario 3, 25\% of each species). Other than during tank drains for scat collections, animals had full access to water. The number of fish represented by all recovered structures was estimated using a "minimum number of individuals" technique (Tollit et al. 2003) for each drain and scat recovered over days 2-16. Diet fed (proportion by mass) was compared with diet estimated using both the split sample frequency of occurrence (SSFO) method (Olesiuk et al. 1990) and a simple biomass reconstruction (BR) method, in which it was assumed prey size egested was identical to that ingested and each drain/scat contributed a variable quantity of prey biomass (Laake et al. 2002). Reconstructed biomass estimates were compared when using the "all structure" technique and when using only otoliths.

\section{Prey soft remains identified in scats using genetic techniques}

Using molecular genetic scatology to study diet is a relatively new and involved technique (Jarman et al. 2004), but it has been successfully utilized to classify morphologically unidentifiable hard parts of salmon from harbor seal scats (Purcell et al. 2004). Many of the biases associated with hard remnant analysis could potentially be investigated using DNA techniques to identify prey from soft material, making this approach very appealing. Our recent collaborative captive study (Deagle et al. 2005) aimed to assess whether prey DNA could reliably be detected from soft remains in scats and whether DNA in scats might be useful in quantifying 
diet. In this study, we collected scats from two female Steller sea lions. The first animal (\#F97HA, mean mass $146 \mathrm{~kg}, 6$ years old) was in the feeding trial for 48 days; and the second animal (\#F00NU, mean mass 131 $\mathrm{kg}, 3$ years old) for 24 days. Four species of prey were fed consistently in the trial: Pacific herring (Clupea pallasii), surf smelt (Hypomesus pretiosus), sockeye salmon (Oncorhynchus nerka), and Californian market squid (Loligo opalescence). The basic daily diet (7-8 kg per day, $\sim 5.5 \%$ of body mass) was fed in two meals (at $~ 9: 30$ and 14:30) and consisted of herring ( $47 \%$ by mass), smelt (34\%), sockeye (13\%), and squid (6\%). This diet was initiated at least 4 days before the first scats were collected. Small subsamples were taken from each scat and the remaining material blended and then also sampled. DNA was extracted and identified to species using polymerase chain reaction (PCR) and denaturing gradient gel electrophoresis. In a preliminary investigation into quantifying diet, proportions of fish DNA present in six scats were evaluated through the screening of PCR clone libraries. See Deagle et al. (2005) for full details of DNA detection and cloning methodology.

\section{Fatty acid signature analysis}

Fatty acid signatures have been shown to be useful in documenting qualitative variations in diet across species, age, and sex class (e.g., Beck et al. 2005) as well as space and time (e.g., Iverson et al. 1997, Walton and Pomeroy 2003). Quantified fatty acid signature analysis (QFASA) is based on an optimization model that has been developed to estimate the species composition of marine mammal diets by matching the fatty acid (FA) signatures of their blubber with those of their potential prey (Iverson et al. 2004). We conducted captive feeding studies (1-9 months each) on seven juvenile female Steller sea lions to evaluate QFASA's ability to identify known mixed-prey diets and to provide information on FA turnover time and deposition rates down the core of the biopsy. For each animal, 2-9 sequential full-depth blubber biopsies were collected mid-flank, following various periods of controlled diet, including 1-4 week pulses of salmon, capelin, eulachon, walleye pollock, or Atka mackerel. Changes in mass and body composition (using $\mathrm{D}_{2} 0$ ) were also measured (Tollit et al. 2003). A key prerequisite of QFASA are the FA calibration coefficients (FACCs), which aim to account for the differential deposition and synthesis of fatty acids during lipid metabolism. These are typically calculated by using FA signatures in blubber after feeding a long-term diet of pure herring. FA-CCs are available for two species of phocid (Iverson et al. 2004), but none are available for otariids. To assess possible differences in fatty acid metabolism across pinnipeds, blubber biopsies were taken from five Steller sea lions after they were fed pure herring diets for 7-9 months. After lipid extraction, flame ionization detector (FID) gas chromatography was used to assess contributions of 68 fatty acid signatures (see Iverson et al. 2004 for a full methodology). 


\section{Results}

\section{Prey hard remains found in scats}

Use of multiple bones (versus only otoliths) increased percent prey recovery (Fig. 1), particularly for salmon. Despite the use of the "all structure" technique, significant differences across prey species in percent recovery (more than tenfold) and passage time (twofold) was documented. Bones in scats were found to consist of a composite of meals eaten 2-148 hours earlier (longer than many phocids) and a single day feeding event was distributed across 1-6 scats (Tollit et al. 2003).

Beaks from the small ( $40 \mathrm{~g}$ ) squid fed were typically found in scats 1-2 days following ingestion, but were also sometimes recovered more than 3 weeks later. A number of meals were subsequently regurgitated, which dramatically reduced the overall recovery of bones in scats, most notably for pollock and salmon. Use of other cranial bones (in addition to otoliths), grading the degree of observed digestion, and the application of experimentally derived grade-specific digestion correction factors (Fig. 2) are fundamental to correctly estimating prey size eaten by Steller sea lions (see also Tollit et al. 2004a,b; Zeppelin et al. 2004).

Regurgitations in scenario 3 of the replicated mixed meal study resulted in fed diets being $\sim 12 \%$ pollock and $\sim 29 \%$ for the remaining species, not $25 \%$ for each species as planned. Analysis of the repeated mixed meal study showed that, despite low contributions of capelin and salmon in scenarios 1 and 2, their presence in subsequent scats was almost always detected when using the "all structure" technique. Consequently, the frequency of occurrence model could not discern the different mixed diet scenarios actually fed. In this particular set of scenarios, the biomass reconstruction (BR) models provided better predictions of the actual amount fed of each species. The BR model using "all structures" did, however, exhibit consistent biases, with capelin consistently underestimated, and salmon and pollock consistently overestimated (Fig. 3). The use of only otoliths to estimate diet resulted in a number of improvements (e.g., salmon) over the "all structure" technique, but also resulted in some poorer predictions (e.g., herring). Capelin, the smallest prey consumed, remained consistently underestimated (Fig. 3).

\section{Prey soft remains identified in scats using genetic techniques}

Our results show prey DNA can be successfully isolated from soft remains, even in cases when the scats were left out in the sun for a number of days. Detection rates (i.e., frequencies of prey DNA occurrence) were extremely high (98\%) when scats were blended together and sampled. When scats were simply subsampled, the detection rates were significantly lower (but still relatively high-89\%). Different prey species were generally detected equally despite the large differences in the amount 


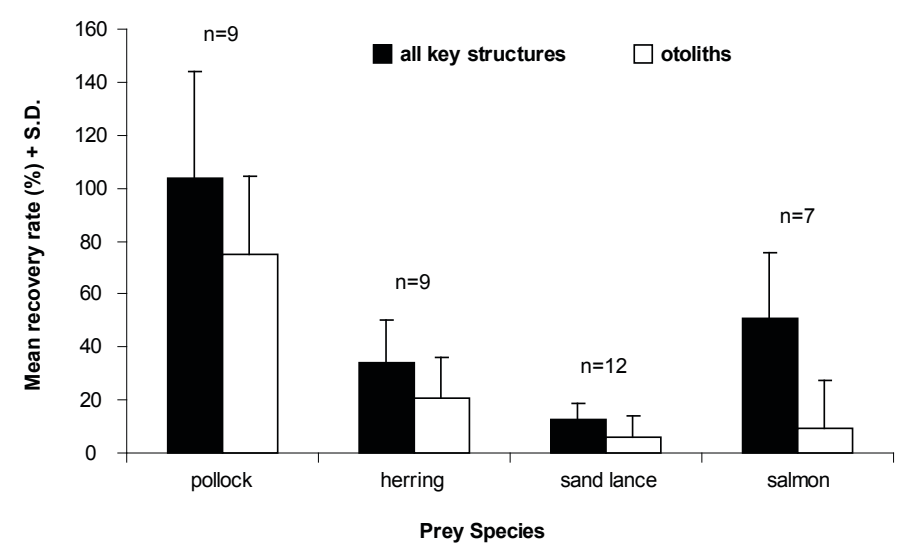

Figure 1. Between-species comparison of mean prey recovery $(\%)$, when using multiple bones (all key structures) versus otoliths only. Data represent multiple feeding trials (n) with two female captive Steller sea lions in which meals containing regurgitated material have been excluded. Adapted from Tollit et al. (2003).

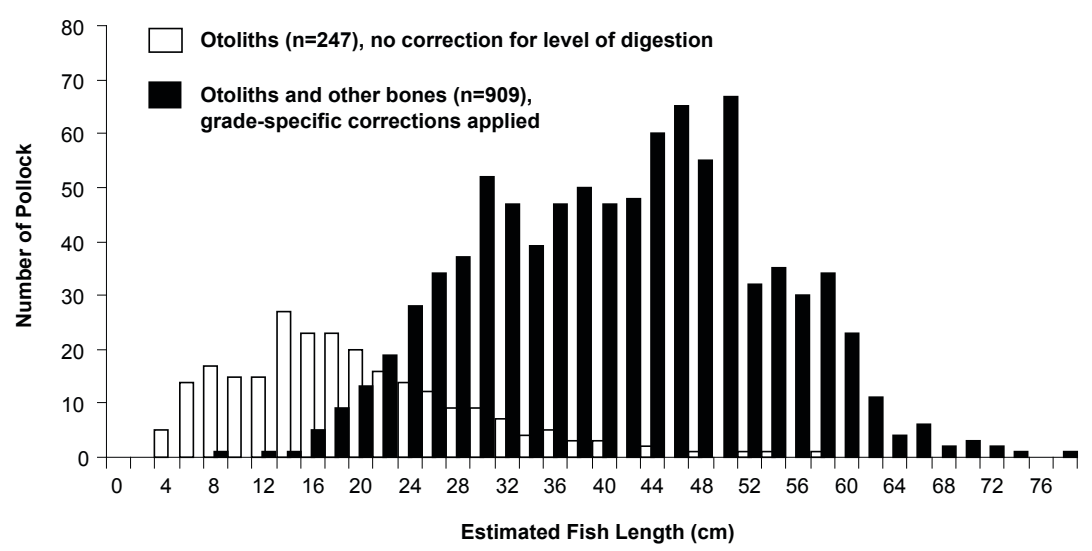

Figure 2. Comparison of two methods to estimate the size of walleye pollock recovered in Steller sea lion scats collected in the field (Southeast Alaska 1993-1999). Fish length predicted from all otoliths regardless of digestive state (mean $F L=20.2 \mathrm{~cm}$ ) are compared with estimates using six additional cranial structures besides otoliths, of which all are in good or fair condition and to which experimentally derived grade-specific correction factors have been applied to account for level of digestion (mean $\mathrm{FL}=42.4 \mathrm{~cm}$ ). 


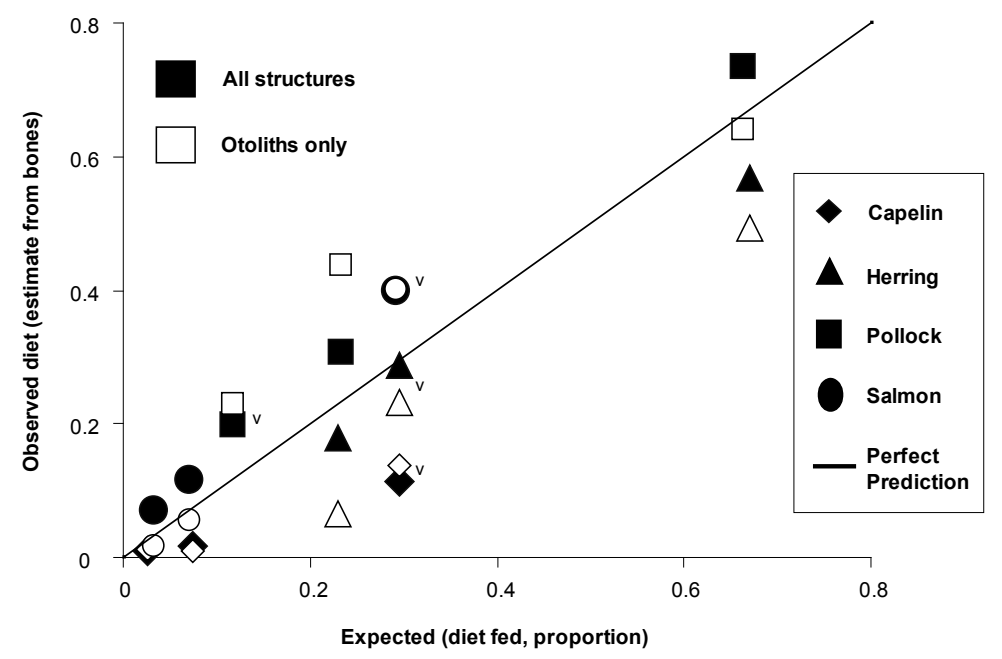

Figure 3. Comparison of using the "all structure" technique versus only otoliths in estimating diet using a biomass reconstruction method (observed diet). Captive Steller sea lions were fed meals of mixed and variable prey composition consistently for 15 days (diet fed). $\mathbf{V}$ denotes data points that include evidence of regurgitated hard remains in $36 \%$ of scats/tank drains.

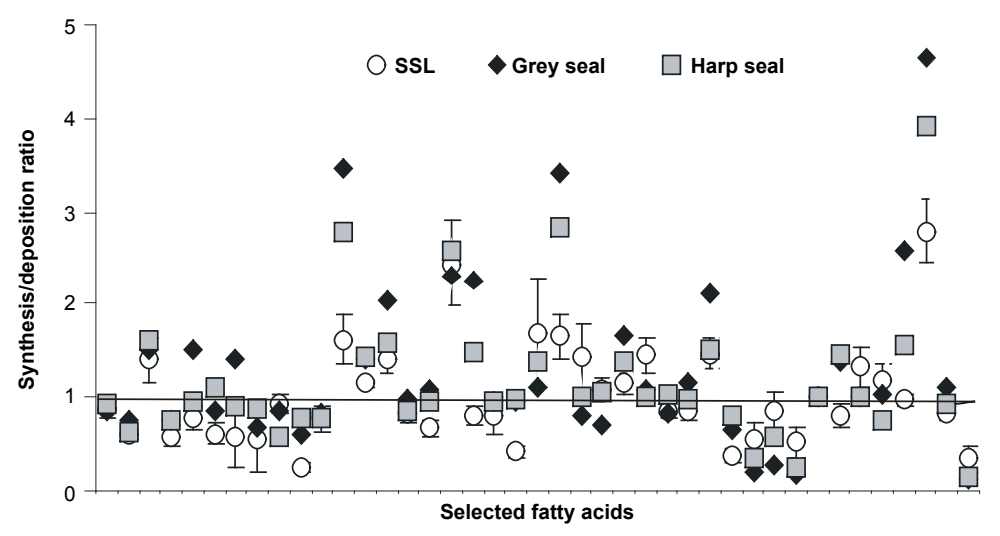

Figure 4. Fatty acid calibration coefficients shown for three pinniped species, including Steller sea lions $(S S L)$. Fatty acids $(n=41)$ ranging from $\mathrm{C} 12.0$ to $\mathrm{C} 24.1 \mathrm{w} 9$ are shown, with the line at 1 indicating the proportion found in the diet was identical to that found in the blubber sample (no synthesis or deposition). Data for grey and harp seals are taken from Iverson et al. (2004). 
of each fed. Proportions of fish DNA present in six scat samples were roughly proportional to the mass of prey consumed, but directional biases were apparent. For example, herring (fed at $50 \%$ of the total fish component) and salmon (fed at $14 \%$ ) were both slightly overestimated (clone predictions: herring, 56-72\%; salmon, 16-28\%), while smelt (fed at $36 \%$ ) was underestimated somewhat, with predictions from clones ranging from $12 \%$ to $32 \%$.

\section{Fatty acid signature analysis}

Optimization of the QFASA model using data from captive animal studies is still ongoing. To date QFASA results were promising, but did result in false identifications of prey, and were dependent on which modeling parameters were used (FA-CCs, number of FAs included, etc.). Preliminary results also showed Steller sea lion FA-CCs were comparable to but not interchangeable with those previously obtained from phocid seals (Fig. 4). Overall, where differences were apparent, Steller sea lion FA-CCs were lower than for those observed for gray and harp seals for fatty acids: C14.1w5, C15.1w8, C16.1w11, C17.0, C17.1, C16.4w1, C18.1w11, $\mathrm{C} 18.1 \mathrm{w} 9, \mathrm{C} 18.3 \mathrm{w} 3, \mathrm{C} 18.4 \mathrm{w} 3, \mathrm{C} 20.5 \mathrm{w} 3, \mathrm{C} 22.2 \mathrm{w} 6$ and $\mathrm{C} 22.5 \mathrm{w} 3$; and higher for fatty acids: C14.1w7, C15.1w6, C20.0, C22.1w7, C22.1w9, C22.1w11, C22.4w6, C24.1w9.

\section{Discussion}

Scat collections may disturb animals resting on land, but they are otherwise noninvasive. Importantly, they typically provide definitive prey species identification and can often be collected in large numbers. Analysis of prey remnants in scats presently remains the best method for assessing prey size, provided levels of digestion are taken into account (Jobling and Breiby 1986). Low recovery of otoliths in sea lion scats has been shown in a number of species (e.g., Dellinger and Trillmich 1988, Gales and Cheal 1992, Tollit et al. 2003), therefore other techniques are needed to supplement dietary data. For example, the use of alternate bones (as well as accounting for the amount of digestion) was demonstrated to be crucial in assessing the extent of overlap between sizes of pollock taken by Steller sea lions compared to that taken by the commercial fishery (Fig. 2, Tollit et al. 2004a). However, while the use of multiple bones increases species recovery rates, species differences (hence potential biases) are not eliminated and enumeration becomes problematic (see Tollit et al. 2003). This is mainly a result of fish bones from single feeding events being spread over multiple (1-6) scats and consequently resulting in the double counting of the same fish. Counting the most numerous paired bone available or the development of new bone-counting techniques to estimate prey numbers eaten may circumvent this particular problem. However, it is important to note that captive feeding studies often report 
information by collapsing data for all scats collected after a meal. A more logical (realistic?) approach would be to provide information at the level of individual scats. For example, while pollock recovery per feeding event was relatively high overall (Fig. 1), it was also distributed across a large number of scats. Nevertheless, the extended scat output we observed in Steller sea lions, and seen also in southern sea lions (D. Rodriguez, CONICET, Mar del Plata, Argentina, pers. comm.), does challenge the assumption that scats necessarily represent just nearshore or recent foraging.

Provided sample sizes are sufficient (estimated for biomass reconstruction to be around 100 samples by Hammond and Rothery [1996]), it is reasonable to assume inherent biases are consistent, permitting comparisons of the relative importance of prey species across time periods or geographical areas. Use of correction factors can negate some biases associated with differential digestion, but regurgitation and crushing by gastroliths or stomach rocks of larger bones confound their easy application. Clearly, given the high intraspecific variability observed, multiple experiments are required to produce useful correction factors and the experiment must be designed to be as realistic as possible. Gastroliths in the Australian sea lion may have been a factor in the low otolith recovery observed in captive feeding studies (Gales and Cheal 1992), as well as from scats collected in the wild. In species that are known to regularly regurgitate material (e.g., California sea lion, Steller sea lion, northern fur seal, Galapagos fur seal), it is important to analyze regurgitate material (either from lavage or from land-based regurgitates) to assess possible biases in size and species consumed, compared to assessments solely from scats (Fea and Harcourt 1997, Kiyota 1999). Apparent biases in exclusively using scat data include underestimating large cephalopods and large fish such as gadoids. Data on at-sea feeding episodes and regurgitation rates (using head-mounted cameras) would be useful in this assessment (see Bowen et al. 2002).

Frequency of occurrence indexes can quickly provide useful dietary information, particularly with large sample sizes (Olesiuk 1990, Sinclair and Zeppelin 2002). Our replicated mixed meal study highlighted the reliability of the "all structure" technique in identifying the presence of four prey fed regularly in widely varying proportions (2.5\%-67.5\%), leading to the split sample frequency of occurrence index (SSFO) to predict all prey were eaten in approximately equal quantities. Olesiuk et al. (1990) recognized SSFO captures the occurrence component of diet and suggested a volume-weighted version. Our results concur that a prey biomass/volume approach is required if fine level diet estimates are required at small scales and within narrow time frames, especially when sample sizes are limited. Thus, while biomass reconstruction generally gave improved predictions of the actual amount fed of each species, systematic biases were observed (Fig. 3), that confirm previous studies (e.g., Harvey 1989; Tollit et al. 1997, 2003) that highlight the need for species-specific numerical 
correction factors. The drawbacks of reconstructing prey biomass include the need for prey remains to be enumerated and measured and the need for bone size to fish size regressions. In addition to captive studies, the use of Monte Carlo diet simulations can provide useful information on the biases of each method and to assess the success of possible solutions (Hammond and Rothery 1996, Arim and Naya 2003), such as the use of numerical correction factors to account for species variability in bone recovery rates.

Analysis of prey hard remains clearly can provide useful dietary information that is difficult to obtain using alternate methods. Time permitting, and if suitable regression equations and digestion correction factors exist, then biomass/volume reconstructions are recommended. Further captive studies are required to assess if prey in individual scats should be considered a random and therefore variable subsample of diet or if the contribution of each scat should be fixed to a predetermined constant (e.g., daily mass consumption or calorific requirement)(Laake et al. 2002). For the sake of comparison, it is important to present results using a variety of indices, including percent numbers, frequency of occurrence, and some measure of contribution by mass. Potentially, an index of relative importance (Harvey 1987) can be calculated combining these indices, whereby species are merely ranked, as opposed to supplying a point estimate that may be potentially biased (see discussion by Laake et al 2002).

While isolating prey DNA from scats and using PCR techniques to identify species is clearly involved and presently more expensive than traditional analysis of prey remnants in scats, it does not require prey hard parts and therefore is likely to be less affected by differential bone retention and digestion. The captive feeding study described (see Deagle et al. 2005 for full details) clearly highlights that further investment is warranted; particularly in determining new genetic markers for prey species of interest, trialing the technique on field collected scat samples, and assessing alternate techniques for quantifying DNA in scats (such as Real Time PCR). Like prey remnant analysis, this approach only reflects shortterm dietary history. Nevertheless, the technique may prove very useful in studies where prey have fragile bones (such as salmonids), where prey have hard parts that are regurgitated (e.g., large cephalopods), where prey have few or no hard parts, or in species such as Australian sea lions in which bones are poorly represented in scats (Gales and Cheal 1992). We note that DNA methods can also provide information on the predator, including animal sex, species (e.g., Reed et al 1997), and theoretically individual identification information.

Animal capture (if possible) clearly provides useful demographic information and dietary data at the individual level, that can be collected on many temporal scales (long term-vibrissae stable isotope analysis; medium term-QFASA muscle and skin stable isotope analysis, short 
term-lavage, enema, cameras). Stable isotope ratio analysis of predator tissues presently provides only trophic level data, but the technique allows one to follow diet changes through time and at different temporal scales (Kurle 2002). Fatty acid signatures have also been useful in documenting both species, as well as spatial and temporal variations in diet (Iverson et al. 1997). While the validation of the QFASA model to quantify diet in Steller sea lions is continuing, preliminary results of this new technique are promising and worth pursuing, particularly to assess biases in traditional methods, the onset of weaning, and the prey that most contribute to lipid reserves. QFASA ideally requires a current and full prey base as well as fatty acid calibration coefficients (FA-CCs). Preliminary results of our study showed Steller sea lion FA-CCs were comparable to but not interchangeable with those previously obtained from phocid seals (Iverson et al. 2004, Fig. 4). Thus it appears either otariid or species-specific FA-CCs are needed or alternatively the comparatively shorter time period herring was fed in the two phocid studies did not result in the full turnover of lipid reserves (i.e., some trace of previous diet remained). Collections of blubber from animals difficult to capture can be obtained remotely using various dart projectors (Barrett-Lennard et al. 1996), but further information is needed to assess if signatures vary around the body and along the length of the blubber core (if only partial samples are collected). Animal capture also allows the ability to deploy cameras. Cameras need to be recovered and are presently somewhat limited by memory capacity, but they can provide useful foraging information, including profitability rates (Bowen et al. 2002), prey types, and search patterns (e.g., benthic, pelagic). Foraging success (intensity) can also be addressed using stomach temperature sensors and, more recently, magnet-based mandibular sensors (Wilson et al. 2002). Overall, while the analysis of prey remnants remains the obvious first step, ideally a suite of techniques should be used to study diet to ensure important components are not missed. Methods and correction factors developed for Steller sea lions can likely be applied to the other four sea lion species, but they should be verified experimentally.

\section{Acknowledgments}

Funding for this project was provided to the North Pacific Universities Marine Mammal Research Consortium by the National Oceanic and Atmospheric Administration and the North Pacific Marine Science Foundation. We would like to thank the marine mammal trainers and staff of the Vancouver Aquarium Marine Science Centre, the contribution of personnel of the Marine Mammal Research Unit, National Marine Mammal Laboratory, Dalhousie University and also S. Crockford of Pacific IDentifications Inc., Victoria. We would also like to express gratitude to the organizations and companies that have donated fish to the project. Work was undertaken in accordance with UBC Animal Care Committee guidelines. 


\section{References}

Arim, M., and D.E. Naya. 2003. Pinniped diets inferred from scats: Analysis of biases in prey occurrence. Can. J. Zool. 81(1):67-73.

Barrett-Lennard, L.G., T.G. Smith, and G.M. Ellis. 1996. A cetacean biopsy system using lightweight pneumatic darts, and its effect on the behavior of killer whales. Mar. Mamm. Sci. 12:14-27.

Beck, C.A., S.J. Iverson, and W.D. Bowen. 2005. Blubber fatty acids of gray seals reveal sex differences in the diet of a size-dimorphic marine carnivore. Can. J. Zool. 83(3):377-388.

Bowen, W.D. 2000. Reconstruction of pinniped diets: Accounting for complete digestion of otoliths and cephalopod beaks. Can. J. Fish. Aquat. Sci. 57:898-905.

Bowen, W.D., J.W. Lawson, and B. Beck. 1993. Seasonal and geographic variation in the species composition and size of prey consumed by grey seals (Halichoerus grypus) on the Scotian shelf. Can. J. Fish. Aquat. Sci. 50:1768-1778.

Bowen W.D., D. Tully, D.J. Boness, D. Bulheier, and G. Marshal. 2002. Prey dependent foraging tactics and prey profitability in a marine mammal. Mar. Ecol. Prog. Ser. 244:235-245.

Cottrell, P.E., and A.W. Trites. 2002. Classifying prey hard part structures recovered from fecal remains of captive Steller sea lions (Eumetopias jubatus). Mar. Mamm. Sci. 18:525-539.

Deagle, B.E., D.J. Tollit, S.N. Jarman, M.A. Hindell, A.W. Trites, and N.J. Gales. 2005. Molecular scatology as a tool to study diet: Analysis of prey DNA in scats from captive Steller sea lions. Mol. Ecol. 14:1831-1842.

Dellinger, T., and F. Trillmich. 1988. Estimating diet composition from scat analysis in otariid seals (Otariidae): Is it reliable? Can. J. Zool. 66:1865-1870.

Fea, N., and R. Harcourt. 1997. Assessing the use of faecal and regurgitate analysis as a means of determining the diet of New Zealand fur seals. In: M. Hindell and C. Kemper (eds.), Marine mammal research in the Southern Hemisphere: Status, ecology and medicine. Surrey Beatty and Sons Ltd., Chipping Norton, pp. 143-150.

Frost, K.J., and L.F. Lowry. 1980. Feeding of ribbon seal (Phoca fasciata) in the Bering Sea in spring. Can. J. Zool. 58:1601-1607.

Gales, N.J., and A.J. Cheal. 1992 Estimating the diet composition of the Australian sea lion (Neophoca cinerea) from scat analysis: An unreliable technique. Wildl. Res. 19:447-455.

Hammond, P.S., and P. Rothery. 1996. Application of computer sampling in the estimation of seal diet. J. Appl. Stat. 23:525-533.

Harvey, J.T. 1987. Population dynamics, annual food consumption, dive behaviors, and movements of harbor seals, Phoca vitulina richardsi, in Oregon. Ph.D. thesis, Oregon State University, Corvallis. 168 pp.

Harvey, J.T. 1989. Assessment of errors associated with harbor seal (Phoca vitulina) fecal sampling. J. Zool. (Lond.) 219:101-111. 
Iverson, S.J., K.J. Frost, and L.F. Lowry. 1997. Fatty acid signatures reveal fine scale structure of foraging distribution of harbor seals and their prey in Prince William Sound, Alaska. Mar. Ecol. Prog. Ser 151:255-271.

Iverson, S.J., C. Field, W.D. Bowen, and W. Blanchard. 2004. Quantitative fatty acid signature analysis: A new method of estimating predator diets. Ecol. Monogr. 74:211-235.

Jarman, S.N., B.E. Deagle, and N.J. Gales. 2004. Group-specific polymerase chain reaction for DNA-based analysis of species diversity and identity in dietary samples. Mol. Ecol. 13:1313-1322.

Jobling, M., and A. Breiby. 1986. The use and abuse of fish otoliths in studies of feeding habits of marine piscivores. Sarsia 71:265-274.

Kiyota, M., C. Kawai, and N. Baba. 1999. Estimation of diet of male northern fur seals (Callorhinus ursinus) based on the analysis of fecal and regurgitated materials. Bull. Nat. Res. Inst. Far Seas Fish 36:1-7.

Kurle, C.M. 2002. Stable-isotope ratios of blood components from captive northern fur seals (Callorhinus ursinus) and their diet: Applications for studying the foraging ecology of wild otariids. Can. J. Zool. 80:902-909.

Laake, J.L., P. Browne, R.L. DeLong, and H.R. Huber. 2002. Pinniped diet composition: A comparison of estimation models. Fish. Bull. U.S. 100:434-477.

Olesiuk, P.F., M.A. Bigg, G.M. Ellis, S.J. Crockford, and R.J. Wigen. 1990. An assessment of the feeding habits of harbour seals (Phoca vitulina) in the Strait of Georgia, British Columbia, based on scat analysis. Can. Tech. Rep. Fish. Aquat. Sci. 1730. 135 pp.

Orr, A.J., and J.T. Harvey. 2001. Quantifying errors associated with using fecal samples to determine the diet of the California sea lion (Zalophus californianus). Can. J. Zool. 79:1080-1087.

Pierce, G.J., and P.R. Boyle. 1991. A review of methods for diet analysis in piscivorous marine mammals. Oceanogr. Mar. Biol. Ann. Rev. 29:409-486.

Purcell, M., G. Mackey, E. LaHood, H. Huber, and L. Park. 2004. Molecular methods for genetic identification of salmonid prey from Pacific harbor seal (Phoca vitulina richardsi) scat. Fish. Bull. U.S. 102:213-220.

Reed, Z., D.J. Tollit, P.M. Thompson, and W. Amos. 1997. Molecular scatology: The use of molecular genetic analysis to assign species, sex and individual identity to seal faeces. Mol. Ecol. 6:225-234.

Sinclair, E.H., and T.K. Zeppelin. 2002. Seasonal and spatial differences in diet in the western stock of Steller sea lions (Eumetopias jubatus). J. Mammal. 83(4):973-990.

Staniland, I.J. 2002. Investigating the biases in the use of hard prey remains to identify diet composition using Antarctic fur seals (Arctocephalus gazella) in captive feeding trials. Mar. Mamm. Sci. 18:223-243.

Tollit, D.J., and P.M. Thompson. 1996. Seasonal and between-year variations in the diet of harbour seals in the Moray Firth, Scotland. Can. J. Zool. 74:11101121. 
Tollit, D.J., S.G. Heaslip, and A.W. Trites. 2004a. Sizes of walleye pollock consumed by the eastern stock of Steller sea lions (Eumetopias jubatus) in Southeast Alaska from 1994-1999. Fish. Bull. U.S. 102:522-532.

Tollit, D.J., S.J. Iverson, S.G. Heaslip, D.A.S. Rosen, and A.W. Trites. 2003. Validation studies of blubber quantitative fatty acid signature analysis (QFASA) with captive Steller sea lions (Eumetopias jubatus). $15^{\text {th }}$ Biennial Conference on the Biology of Marine Mammals, Greensboro, NC, 14-19 December 2003, Abstract book. Society for Marine Mammalogy.

Tollit, D.J., M. Wong, A.J. Winship, D.A.S. Rosen, and A.W. Trites. 2003. Quantifying errors associated with using prey skeletal structures from fecal samples to determine the diet of the Steller sea lion (Eumetopias jubatus). Mar. Mamm. Sci. 19:724-744.

Tollit, D.J., S.G. Heaslip, T.K. Zeppelin, R. Joy, K.A. Call, and A.W. Trites. 2004b. Improving size estimates of walleye pollock and Atka mackerel consumed by Steller sea lions using digestion correction factors and bones recovered in scats. Fish. Bull. U.S. 102:498-508.

Tollit, D.J., M. Steward, P.M. Thompson, G.J. Pierce, M.B. Santos, and S. Hughes. 1997. Species and size differences in the digestion of otoliths and beaks: Implications for estimates of pinniped diet composition. Can. J. Fish. Aquat. Sci. 54:105-119.

Walton, M.J., and P. Pomeroy. 2003. Blubber fatty acid profiles detect inter-annual variation in the diet of grey seals (Halichoerus grypus). Mar. Ecol. Prog. Ser. 248:257-266.

Wilson, R.P., A. Steinfurth, Y. Ropert-Coudert, A. Kato, and M. Kurita. 2002. Lipreading in remote subjects: An attempt to quantify and separate ingestion, breathing and vocalization in free-living animals using penguins as a model. Mar. Biol. 140:17-27.

Zeppelin, T.K., D.J. Tollit, K.A. Call, T.J. Orchard, and C.J. Gudmundson. 2004. Sizes of walleye pollock and Atka mackerel consumed by the western stock of Steller sea lions (Eumetopias jubatus) in Alaska from 1999-2001. Fish. Bull. U.S. 102:509-521. 
